\title{
ЭПИЛЕПТОЛОГИЯ
}

УДК 616.853-056.34:616.8-008.64:612.82:612.017.34:577.121-044.342

Для цитирования: Капустина Т.В., Иванов М.В., Липатова Л.В., Тумова М.А. Нейровизуализационные особенности коморбидных депрессивных расстройств у больных эпилепсией. Сибирский вестник психиатрии и наркологии. 2020; 1 (106): 97-104. https://doi.org/10.26617/1810-3111-2020-1(106)-97-104

\section{Нейровизуализационные особенности коморбидных депрессивных расстройств у больных эпилепсией}

\author{
Капустина Т.В.', Иванов М.В.' ${ }^{1}$ Липатова Л.В.' ${ }^{2}$ Тумова М.А. ${ }^{1}$ \\ ${ }^{1}$ Национальный медицинский исследовательский центр психиатрии и неврологии им. В.М. Бехтерева \\ Россия, 192019, Санкт-Петербург, ул. Бехтерева, 3 \\ ${ }^{2}$ Национальный медицинский исследовательский иеентр им. В.А. Алмазова \\ Россия,197341, Санкт-Петербург, ул. Аккуратова, 2
} \begin{abstract}
PEЗЮME
Современные структурные и функциональные исследования головного мозга оказали огромное влияние на диагностику и лечение эпилепсии и ассоциированных с ней психических расстройств, так как позволяют выявить изменения в мозговых структурах, ответственных за эпилептогенез и развитие аффективных нарушений. Структурный и межрегиональный нейроимиджинг продемонстрировал высокий клинический потенциал, так как при аномалиях аберрантных нейронных связей могут развиваться различные психические расстройства. Цель исследования: изучить структурно-морфологические и метаболические особенности головного мозга больных эпилепсией и ассоциированной депрессией. Материал исследования: 142 больных эпилепсией (БЭ), разделенных на две группы: 69 пациентов БЭ с коморбидными депрессивными расстройствами (БЭД) и 73 БЭ без депрессии. Методы: клинико-психопатологический, неврологический, психометрический, нейровизуализационный - магнитно-резонансная томография головного мозга (МРТ) с напряжением магнитного поля 3 Тесла, диффузионно-тензорная МРТ головного мозга с трактографией, одновоксельная протонная спектроскопия гиппокампов. Результаты. У БЭД выявлено изменение архитектоники различных отделов головного мозга в виде снижения плотности серого вещества и фракционной анизотропии проводящих путей белого вещества с обеднением их структуры в кортикоспинальном, лобно-затылочных трактах, преимущественно справа, а также в трактах форникса и мозолистого тела, снижение уровня основных метаболитов головного мозга (креатина, холина, $\mathrm{N}$-ацетиласпартата) в сравнении с контрольными группами больных. Заключение. В результате настоящего исследования уточнены особенности топографии нейродегенеративных изменений головного мозга. Получены данные о снижении содержания основных церебральных метаболитов гиппокампа, отражающие нарушение функционирования нейронной сети на разных уровнях и свидетельствующие об единых патогенетических механизмах эпилепсии и депрессии, что важно для определения лечебной тактики ведения пациентов с эпилепсией и коморбидной депрессией.
\end{abstract}

Ключевые слова: эпилепсия, депрессия, нейровизуализация, головной мозг, нейродегенеративные изменения головного мозга, трактография, спектроскопия.

\section{ВВЕДЕНИЕ}

Эпилептология находится на стыке двух специальностей: неврологии и психиатрии, поскольку эпилепсия, являясь хроническим заболеванием, характеризуется полиморфной клинической картиной, представляющей собой сложный комплекс симптомов, в котором неврологические проявления тесно переплетаются с психическими и соматическими расстройствами $[1,2,3,4]$. Депрессивные расстройства (ДР), занимающие одно из ведущих мест в ряду ассоциированных с эпилепсией психических расстройств, приводят к утяжелению основного заболевания, повышают суици- дальный риск и снижают качество жизни больных $[5,6,7,8]$.

Современные структурные и функциональные исследования головного мозга оказали колоссальное влияние на диагностику и лечение эпилепсии и ассоциированных с ней психических расстройств, так как позволяют выявить изменения в мозговых структурах, ответственных за эпилептогенез и развитие аффективных нарушений $[9,10,11,12]$. В последние годы появилось новое представление о совокупности структурно-функциональных связей в нервной системе организма - коннектомика. 
Организация нервных сетей - одна из фундаментальных основ церебральной патологии, которая обусловлена нарушением связей [13, $14,15]$. Структурный и межрегиональный нейроимиджинг продемонстрировал высокий клинический потенциал, так как было доказано, что при аномалиях аберрантных нейронных связей («faulty wiring») могут развиваться различные психические расстройства [16, 17]. Имиджинговая методология становится перспективной для описания паттерна структурных и функциональных связей в мозге человека [13]. Единые механизмы патогенеза и коморбидности неврологических и психических заболеваний (в первую очередь депрессии) определяют общие подходы к фармакотерапии.

\section{ЦЕЛЬ ИССЛЕДОВАНИЯ}

Изучить клинические особенности и механизмы развития (патогенеза) коморбидных депрессивных расстройств у больных эпилепсией для повышения качества диагностики и оптимизации терапии с использованием патогенетически обоснованных методов лечения.

\section{МАТЕРИАЛЫ И МЕТОДЫ}

Обследованы 142 больных эпилепсией (БЭ), которые были разделены на две группы. Основную группу (ОГ) составили 69 пациентов БЭ с коморбидными депрессивными расстройствами (БЭД). Для пациентов основной группы (БЭД) введены дополнительные критерии включения: 1) наличие диагноза ДР по критериям МКБ-10 из рубрик F32.0 - Депрессивный эпизод легкой степени, F32.1 - Депрессивный эпизод средней степени; 2) наличие в анамнезе одного и более депрессивных эпизодов. В контрольную группу (КГ) вошли больные эпилепсией (БЭ) без депрессивных расстройств (73 человека). Использовались методы исследования: 1) психопатологический, 2) неврологический, 3) психометрический, включающий использование Госпитальной шкалы оценки депрессии - HADS (1983), 4) нейровизуализационный, включая магнитно-резонансную томографию головного мозга (МРТ) с напряжением магнитного поля 3 Тесла, диффузионнотензорную МРТ с трактографией, одновоксельную протонную спектроскопию гиппокампов.

\section{РЕЗУЛЬТАТЫ И ОБСУЖДЕНИЕ}

При анализе данных, полученных с помощью МРТ головного мозга, установлено, что более выраженными изменениями головного мозга являлись аномалии развития и изменения гиппокампов. Аномалии развития выявлены у 45 больных $(65,2 \%)$ эпилепсией с ассоциированными депрессивными расстройствами и у 30
$(41,1 \%)$ больных эпилепсией $(p(\phi) \leq 0,01)$. Изменение гиппокампов наблюдалось у 57 (82,6\%) БЭД и у $43(58,9 \%)$ БЭ $(\mathrm{p}(\phi) \leq 0,01)$. Обнаружены различия в выраженности и частоте встречаемости изменений головного мозга в виде наружной гидроцефалии: в группе БЭД - у 33 $(47,8 \%)$ больных, в группе БЭ - у $36(49,3 \%)$ больных $(\mathrm{p}(\phi) \leq 0,05)$; в виде внутренней гидроцефалии: в группе БЭД - у 14 (20,3\%) больных, в группе БЭ - у $17(23,3 \%)$ больных $(\mathrm{p}(\phi) \leq 0,05)$; в виде очаговых изменений: у $35(50,7 \%)$ больных - в группе БЭД, у 37 (50,7\%) больных в группе БЭ $(\mathrm{p}(\phi)=1)$.

Результаты трактографии у исследуемых больных также имели статистически значимые различия. Выбор трактов происходил на основе ранее полученных данных различных авторов и после тщательного анализа. Для данного исследования были выбраны следующие тракты: лобно-затылочные тракты (справа, слева), кортикоспинальный тракт (справа, слева), тракт мозолистого тела, форникса, тракт таламуса (справа, слева).

При сравнении фракционной анизотропии (ФА) трактов головного мозга у больных эпилепсией с расстройствами депрессивного спектра и больных эпилепсией были выявлены статистически достоверные различия. В группе БЭД ФА тракты форникса и мозолистого тела были ниже, чем в группе больных эпилепсией. В группе больных эпилепсией с расстройствами депрессивного спектра ФА кортикоспинальных трактов справа и слева ( $\mathrm{t}=1,99 ; \mathrm{p} \leq 0,05$ слева и $\mathrm{t}=2,75 ; \mathrm{p} \leq 0,01$ справа); лобнозатылочных трактов справа и слева ( $\mathrm{t}=23,82$; $\mathrm{p} \leq 0,01$ справа и $\mathrm{t}=19,22 ; \mathrm{p} \leq 0,01$ слева), а также трактов таламуса справа и слева $(\mathrm{t}=16,78$; $\mathrm{p} \leq 0,01$ справа и $\mathrm{t}=11,62 ; \mathrm{p} \leq 0,01$ слева) была ниже, чем в группе больных эпилепсией. В общей группе (ОГ) при сравнении ФА трактов справа и слева выявлена тенденция снижения ФА $(\mathrm{t}=4,1808 ; \mathrm{p}=0,05)$ справа, достоверных различий не выявлено $(\mathrm{t}=0,6547 ; \mathrm{p} \leq 0,05)$.

На основании полученных данных обнаружены общие тенденции для каждой группы больных эпилепсией с расстройствами депрессивного спектра с различными депрессивными симптомокомплексами. Так, в группе БЭ с астенодепрессивным симптомокомплексом выявлено снижение фракционной анизотропии в проводящих путях задних и переднецингулярных отделов, больших и малых щипцов (в трактах, обеспечивающих межполушарную связь), кортикоспинальном тракте слева. 
В группе БЭ с депрессивно-ипохондрическим симптомокомплексом дефицит трактов установлен в колене мозолистого тела, форниксе, нижнем лобно-затылочном пучке справа. В группе БЭ с депрессивно-дисфорическим симптомокомплексом отмечалось снижение ФА в тракте мозолистого тела и кортикоспинальном тракте справа. Во всех трех группах выявлено снижение ФА в трактах таламуса справа.

Далее приводятся результаты магнитнорезонансной одновоксельной протонной спектроскопии гиппокампов в группах исследуемых больных. В постпроцессинговой обработке вычислялись пики основных метаболитов большой «тройки»: $\mathrm{N}$-ацетиласпартата (NAA), маркера нейродегенерации, маркера клеточных мембран, холина (Cho), маркера клеточных мембран, компонента фосфолипидного метаболизма, отражающего состояние пролиферации клеток, креатина (Cr), маркера аэробного метаболизма клеток головного мозга с последующей их обработкой. Результаты вычисления соотношения этих метаболитов представлены в таблице 1.

Т а б л и ц а 1. Соотношение основных метаболитов у больных основной группы с эпилепсией и коморбидными депрессивными расстройствами (БЭД) и больных контрольной группы с депрессией (БЭ)

\begin{tabular}{|c|c|c|c|}
\hline Показатель & БЭД & БЭ & $\mathrm{p}(\mathrm{t})$ \\
\hline \multicolumn{4}{|c|}{ Соотношение ацетиласпартат/холин (NAA/Cho) } \\
\hline Справа $(\mathrm{M} \pm \sigma)$ & $1,22 \pm 0,12$ & $1,08 \pm 0,10$ & $\leq 0,01 * *$ \\
\hline Слева $(\mathrm{M} \pm \sigma)$ & $1,26 \pm 0,14$ & $1,16 \pm 0,11$ & $\leq 0,01 * *$ \\
\hline $\mathrm{p}(\mathrm{t})$ & $\geq 0,05$ & $\leq 0,01 * *$ & - \\
\hline \multicolumn{4}{|c|}{ Соотношение ацетиласпартат/креатин (NAA/Cr) } \\
\hline Справа $(\mathrm{M} \pm \sigma)$ & $1,44 \pm 0,12$ & $1,24 \pm 0,06$ & $\leq 0,01 * *$ \\
\hline Слева $(\mathrm{M} \pm \sigma)$ & $1,46 \pm 0,13$ & $1,41 \pm 0,13$ & $\leq 0,05^{*}$ \\
\hline $\mathrm{p}(\mathrm{t})$ & $>0,05$ & $\leq 0,01 * *$ & - \\
\hline \multicolumn{4}{|c|}{ Соотношение холин/креатин (Cho/Cr) } \\
\hline Справа $(\mathrm{M} \pm \sigma)$ & $1,30 \pm 0,11$ & $1,73 \pm 0,10$ & $\leq 0,01 * *$ \\
\hline Слева $(\mathrm{M} \pm \sigma)$ & $1,44 \pm 0,14$ & $1,30 \pm 0,15$ & $\leq 0,01 * *$ \\
\hline $\mathrm{p}(\mathrm{t})$ & $\leq 0,01 * *$ & $\leq 0,01 * *$ & - \\
\hline
\end{tabular}

Из таблицы 1 видно, что показатели основных метаболитов различались в группах. Показатель NAA/Cho справа в основной группе составил $1,08 \pm 0,10$ и оказался достоверно ниже $(\mathrm{p}(\mathrm{t}) \leq 0,01)$, чем NAA/Cho слева - $1,16 \pm 0,11$. В контрольной группе таких различий не выявлено $(\mathrm{p}(\mathrm{t}) \geq 0,05)$. Показатель NAA/Cho справа и слева был значительно ниже, чем в группе БЭ $(\mathrm{p}(\mathrm{t}) \leq 0,01)$, что может указывать на наличие нейродегенеративного процесса в гиппокампе.

Показатель NAA/Cr также отличался справа и слева в группе ОГ и составил $1,24 \pm 0,06$ и $1,41 \pm 0,13$ соответственно. В группе КГ показатель $\mathrm{NAA} / \mathrm{Cr}$ справа и слева различий не имел. Показатель NAA/Cr был достоверно ниже, чем в КГ $(\mathrm{p}(\mathrm{t}) \leq 0,01)$, причем как справа, так и слева.

Различия значений $\mathrm{Cho} / \mathrm{Cr}$ справа и слева были обнаружены в группе ОГ и КГ. В ОГ отмечалось повышение показателя $\mathrm{Cho} / \mathrm{Cr}$ справа $(1,73 \pm 0,10)$ по сравнению со значением этого показателя слева $(1,30 \pm 0,15 ;(\mathrm{p}(\mathrm{t}) \leq 0,01)$. Показатель Cho/Cr справа в ОГ был выше, чем в КГ. Показатель $\mathrm{Cho} / \mathrm{Cr}$ также значительно отличался, его значения в группе БЭД были выше
$(1,30 \pm 0,15 ; \quad \mathrm{p}(\mathrm{t}) \leq 0,01), \quad$ чем $\quad$ в $\quad$ группе БЭ $(1,44 \pm 0,14 ; \mathrm{p}(\mathrm{t}) \leq 0,01)$.

На рисунке 1 представлено соотношение значений метаболитов NAA/Cho справа и слева, измеряемых в гиппокампе с помощью одновоксельной протонной спектроскопии гиппокампов с коротким временем отклика в группах. Рисунок 1 демонстрирует, что в группе БЭД показатель NAA/Cho был ниже, чем в группе БЭ.

На рисунке 2 показано соотношение значений метаболитов $\mathrm{Naa} / \mathrm{Cr}$ в группах БЭД и БЭ справа и слева, измеряемых в гиппокампе с помощью одновоксельной протонной спектроскопии гиппокампов с коротким временем отклика. Данные, представленные на рисунке 2, отражают, что показатель NAA/Cr у БЭД значительно ниже средних значений у БЭ.

На рисунке 3 продемонстрировано соотношение значений метаболитов $\mathrm{Cho/Cr}$ в группах БЭД и БЭ справа и слева, измеряемых в гиппокампе с помощью одновоксельной протонной спектроскопии гиппокампов с коротким временем отклика. Соответственно результатам исследования показатель $\mathrm{Cho/Cr}$ справа в группе БЭД выше, чем в группе БЭ. 


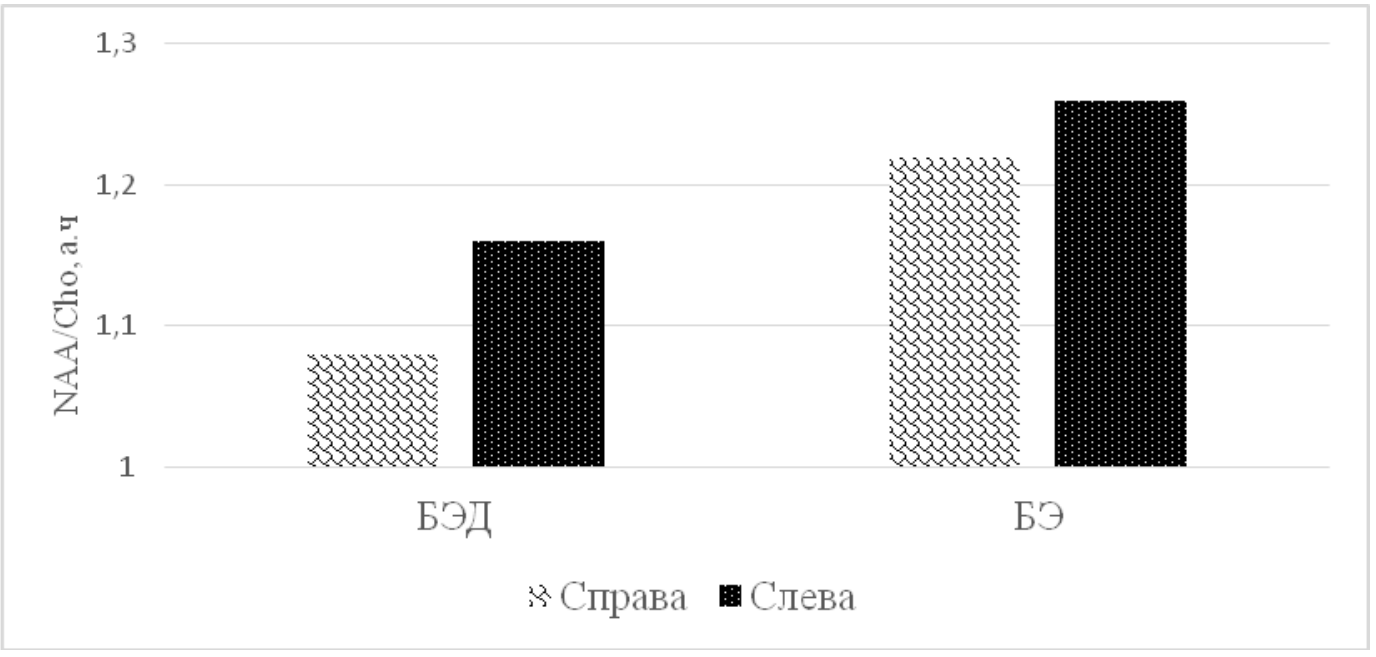

Р и с у н о к 1. Соотношение метаболитов NAA/Cho справа и слева в гиппокампе в основной группе больных эпилепсией и коморбидными депрессивными расстройствами (БЭД) и в контрольной группе больных депрессией (БЭ)

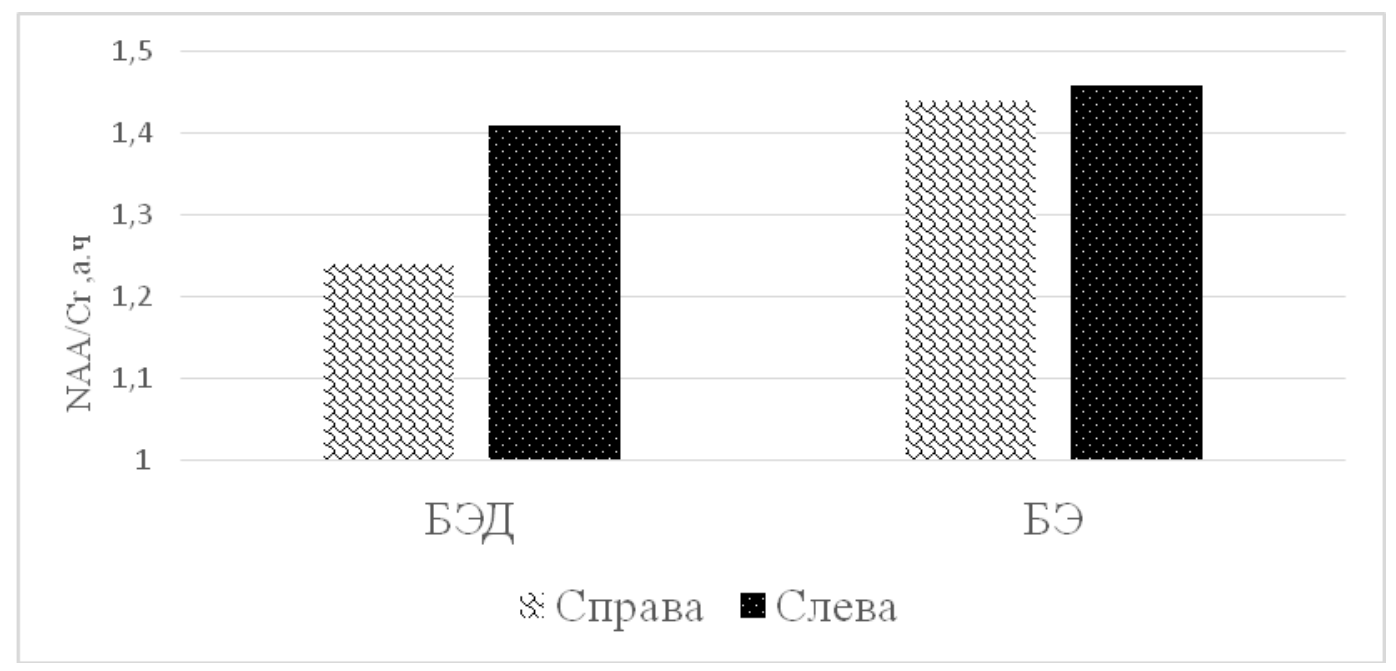

Р и с у н о к 2. Соотношение метаболитов NAA/Cr справа и слева в гиппокампе в основной группе больных эпилепсией и коморбидными депрессивными расстройствами (БЭД) и в контрольной группе больных депрессией (БЭ)

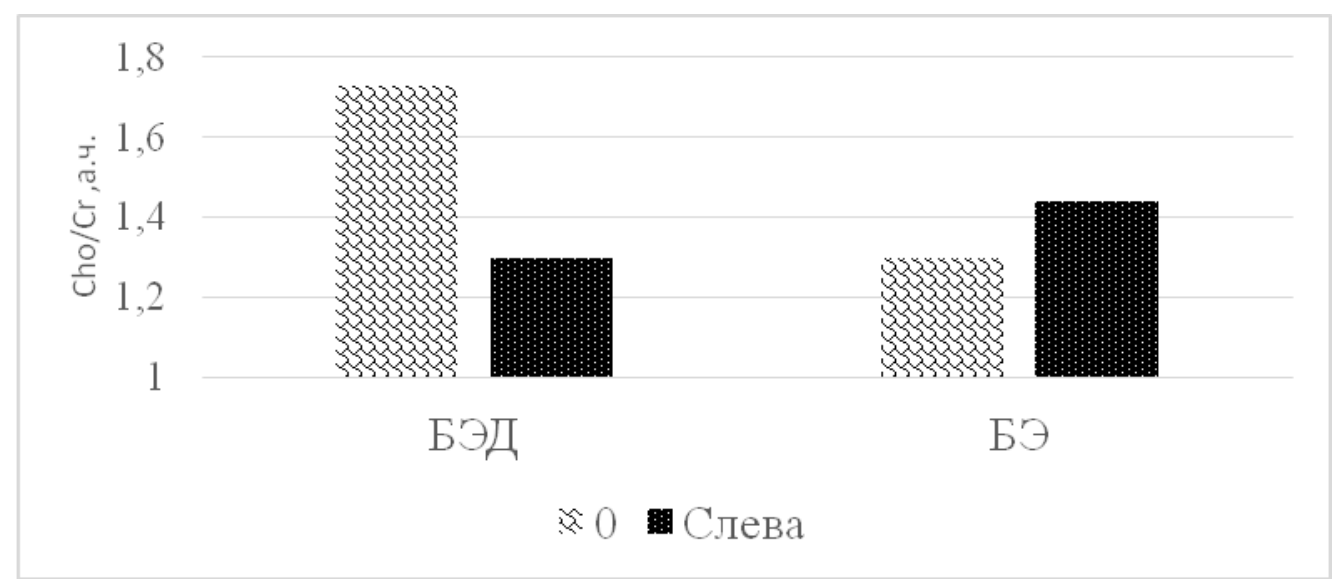

Р и с у н о к 3. Соотношение метаболитов Cho/Cr справа и слева в гиппокампе в основной группе больных эпилепсией и коморбидными депрессивными расстройствами (БЭД) и в контрольной группе больных депрессией (БЭ) 


\section{ЗАКЛЮЧЕНИЕ}

Установленное снижение уровня основных метаболитов головного мозга у больных эпилепсией с ассоциированными депрессивными расстройствами, достигающее минимальных значений при сочетании этих заболеваний, свидетельствует об общих патогенетических механизмах эпилепсии и депрессии и усилении метаболических нарушений при их сочетании.

Несмотря на высокую встречаемость депрессивных проявлений у больных эпилепсией (в 50\% случаев), эти расстройства зачастую остаются нераспознанными в силу как атипичности проявлений, так и ввиду ошибочной диагностики: они трактуются как нежелательные явления терапии антиэпилептическими препаратами или как когнитивные и поведенческие нарушения вследствие эпилепсии [4, 5, 18]. Недооценка данной проблемы и неправильная тактика ведения таких пациентов приводят к целому ряду значимых социальных последствий, увеличению прямых и непрямых расходов на здравоохранение $[4,5,6]$. В результате настоящего исследования уточнены особенности топографии нейродегенеративных изменений головного мозга, получены данные о снижении содержания основных церебральных метаболитов гиппокампа, отражающие нарушение функционирования нейронной сети на разных уровнях.

\section{КОНФЛИКТ ИНТЕРЕСОВ}

Авторы заявляют об отсутствии явных и потенциальных конфликтов интересов в связи с публикацией данной статьи.

\section{ИСТОЧНИК ФИНАНСИРОВАНИЯ}

Авторы заявляют об отсутствии финансирования при проведении исследования.

\section{СООТВЕТСТВИЕ ПРИНЦИПАМ ЭТИКИ}

Исследование проведено с соблюдением норм современной биомедицинской этики и этических стандартов, разработанных в соответствии с Хельсинской декларацией ВМА, и утверждено Локальным этическим комитетом СанктПетербургского научно-исследовательского института им. В.М. Бехтерева (протокол № 11 от 17.11.2016 г.).

\section{ЛИТЕРАТУРА}

1. Тиганов А.С. Эпилепсия. Руководство по психиатрии: В 2-х т. / под ред. А.С. Тиганова. М. : Медицина, 1999; 2: 12-56.

2. Карлов В.А. Эпилепсия как клиническая и нейрофизиологическая проблема. Журнал неврологии и психиатрии им. С.С. Корсакова. 2000; 100 (9): 7-15.

3. Калинин В.В. Коррекция аффективных и когнитивных нарушений у больных эпилепсией и значение ламотриджина. Неврология, нейропсихиатрия, психосоматика. 2013; 5 (2): 78-83.

4. Киссин М.Я. Клиническая эпилептология. 2-е изд. М. : ГЭОТАР-Медиа, 2011: 252.

5. Незнанов Н.Г., Киссин М.Я. Психические расстройства при эпилепсии / под ред. Т.Б. Дмитриевой, В.Н. Краснова, Н.Г. Незнанова и др. М. : ГОЭТАР-Медиа, 2009: 637-651.

6. Castro S., Baroni G., Martins W., Palmini A., Bisol L. Suicide risk, temperament traits, and sleep quality in patients with refractory epilepsy. Epilepsy $\mathrm{Be}$ hav. 2018 Mar; 80: 254-258. DOI: 10.1016/j.yebeh.2018.01.022

7. Калинин В.В., Железнова Е.В., Земляная А.А., Соколова Л.В., Субботин К.Ю. Депрессии при эпилепсии: распространенность, факторы риска, симптоматика и терапия. Эпилепсия и пароксизмальные состояния. 2017; 9 (3): 47-53. DOI: 10.17749/2077-8333.2017.9.3.047-053

8. Goncalves E.B., Cendes F. Depression in patients with refractory temporal lobe epilepsy. Arq Neuropsiquiatr. 2011 Oct; 69(5): 775-7. DOI: 10.1590/s0004-282x2011000600010

9. Иванов М.В., Акименко М.А. Опыт изучения нейроморфологического субстрата аффективных расстройств в связи с проблемой терапевтической резистентности. Психиатрия и психофармакотерапия. 2003; 5(2): 56-73.

10. Hibar D.P., Westlye L.T., Doan N.T. et al. Cortical abnormalities in bipolar disorder: an MRI analysis of 6503 individuals from the ENIGMA Bipolar Disorder Working Group. Mol Psychiatry. 2018 Apr; 23(4): 932-942. doi: 10.1038/mp.2017.73

11. Киссин М.Я., Ананьева Н.И., Шмелева Л.М., Ежова Р.В. Особенности нейроморфологии тревожных и депрессивных расстройств при височной эпилепсии. Обозрение психиатрии и медицинской психологии им. В.М. Бехтерева. 2012; 2: $11-17$.

12. Шамрей В.К., Труфанов Г.Е., Абриталин Е.Ю., Корзенев А.В., Фокин В.А., Тарумов Д.А., Днов К.В., Лебедев А.В., Ефимцев А.Ю., Меньшикова С.В. Современные методы нейровизуализации в диагностике депрессивных расстройств. Вестник Российской Военно-медицинской академии. 2010; 1(29): 37-45.

13. Гуляева Н.В. Нейропластичность и эпилепсия: современные концепции и механизмы коморбидности эпилепсии и депрессии. Журнал неврологии и психиатрии им. С.С. Корсакова. 2015; 115(12): 148-153.

14. Сеунг С. Коннектом. Как мозг делает нас тем, что мы есть: пер. с англ. М. : БИНОМ, Лаборатория знаний, 2014: 440.

15. Gong Q., He Y. Depression, neuroimaging and connectomics: a selective overview. Biol Psychiatry. 2014 Aug; 77(3): 223-235. DOI: 10.1016/j.biopsych.2014.08.009

16. Irimia A., Wang B., Aylward S.R. et al. Neuroimaging of structural pathology and connectomics in 
traumatic brain injury: toward personalized outcome prediction. Neuroimage Clin. 2012 Aug 24; 1(1): 1-17. doi: 10.1016/j.nicl.2012.08.002.

17. Irimia M., Weatheritt R.J., Ellis J. et al. A highly conserved program of neuronal microexons is misregulated in autistic brains. Cell. 2014 Dec; 159(7): 1511-23. DOI: 10.1016/j.cell.2014.11.035

18. Калинин В.В., Железнова Е.В., Земляная А.А., Соколова Л.В., Субботин К.Ю. Депрессии при эпилепсии: распространенность, факторы риска, симптоматика и терапия: Электронный ресурс. Эпилепсия и пароксизмальные состояния. 2017; 9 (3): 47-53. DOI: 10.17749/2077-8333.2017.9.3.047053

Поступила в редакцию 21.10.2019 Утверждена к печати 27.01.2020

Капустина Татьяна Владимировна - к.м.н., младший научный сотрудник отделения лечения больных с органическими психическими расстройствами и эпилепсией ФГБУ «Национальный медицинский исследовательский центр психиатрии и неврологии имени В.M. Бехтерева». ORCID ID 0000-0001-8627-7550. Researcher ID T-1398-2018.

Иванов Михаил Владимирович - д.м.н., профессор, руководитель отделения биологической терапии психически больных ФГБУ «Национальный медицинский исследовательский центр психиатрии и неврологии им. B.М. Бехтерева». profmikhailivanov@gmail.com

Липатова Людмила Валентиновна - д.м.н., профессор кафедры неврологии и психиатрии, Институт медицинского образования, ФГБУ «Национальный медицинский исследовательский центр им. B.A. Алмазова». ORCID ID 0000-0001-9988-3525. Scopus Author ID 36892509600. Researcher ID M-5928-2018. epilepsynet@yandex.ru

Тумова Марианна Анатольевна - младший научный сотрудник отделения биологической терапии психически больных ФГБУ «Национальный медицинский исследовательский центр психиатрии и неврологии им. B.М. Бехтерева».marianna_tumova@mail.ru

Капустина Татьяна Владимировна, kapustina.tv7@gmail.com 
For citation: Kapustina T.V., Ivanov M.V., Lipatova L.V., Tumova M.A. Neuroimaging features of comorbid depressive disorders in patients with epilepsy. Siberian Herald of Psychiatry and Addiction Psychiatry. 2020; 1 (106): $97-$ 104. https://doi.org/10.26617/1810-3111-2020-1(106)-97-104

\title{
Neuroimaging features of comorbid depressive disorders in patients with epilepsy
}

\section{Kapustina T.V. ${ }^{1}$, Ivanov M.V.' ${ }^{1}$ Lipatova L.V.' ${ }^{1}$ Tumova M.A. ${ }^{2}$}

\author{
${ }^{1}$ V.M. Bekhterev National Medical Research Center of Psychiatry and Neurology \\ Bekhterev Street 3, 192019, St. Petersburg, Russian Federation \\ ${ }^{2}$ V.A. Almazov National Medical Research Center \\ Akkuratov Street 2, 197341, St. Petersburg, Russian Federation
}

\begin{abstract}
Modern structural and functional investigations of the brain have had a huge impact on the diagnosis and treatment of epilepsy and its associated mental disorders, as it allows to identify changes in the brain structures responsible for epileptogenesis and development of affective disorders. Structural and interregional neuroimaging has demonstrated a high clinical potential, since various mental disorders can develop with abnormalities of aberrant neural connections. Objective: to study the structural-morphological and metabolic features of the brain of patients with epilepsy and associated depression. Material of the study: 142 patients with epilepsy (EP), divided into two groups: 69 patients with epilepsy with comorbid depressive disorders (EPD) and 73 EP without depression. Methods: clinicalpsychopathological, neurological, psychometric, neuroimaging-magnetic resonance imaging of the brain (MRI) with a magnetic field voltage of 3 Tesla, diffusion-tensor brain MRI with tractography, single-voxel proton spectroscopy of hippocampus. Results. EPD showed a change in the architectonics of various parts of the brain in the form of a decrease in the density of gray matter and fractional anisotropy of the conducting pathways of white matter with a depletion of their structure in the corticospinal, frontooccipital tracts, mainly on the right, as well as in the tracts of the fornix and corpus callosum, lowering the level of the main metabolites of the brain (creatine, choline, $\mathrm{N}$-acetyl aspartate) in comparison with the control groups of patients. Conclusion. As a result of this study, the features of the topography of neurodegenerative changes in the brain are clarified. Data were obtained on a decrease in the content of the main cerebral metabolites of the hippocampus, reflecting impaired functioning of the neural network at different levels and indicating the unified pathogenetic mechanisms of epilepsy and depression, which is important for determining the therapeutic tactics of managing patients with epilepsy and comorbid depression.
\end{abstract}

Keywords: epilepsy, depression, neuroimaging, brain, neurodegenerative changes in the brain, tractography, spectroscopy.

\section{REFERENCES}

1. Tiganov A.S. Epilepsiya. Rukovodstvo po psikhiatrii [Epilepsy. Guide to Psychiatry]: In two volumes / edited by A.S. Tiganov. Moscow: Medicine, 1999; 2: 12-56 (in Russian).

2. Karlov V.A. Epilepsiya kak klinicheskaya i neyrofiziologicheskaya problema [Epilepsy as a clinical and neurophysiological problem]. Zhurnal nevrologii $i$ psikhiatrii imeni S.S. Korsakova S.S. Korsakov Journal of Neurology and Psychiatry. 2000; 100 (9): 7-15 (in Russian).

3. Kalinin V.V. Korrektsiya affektivnykh i kognitivnykh narusheniy u bol'nykh epilepsiyey i znacheniye lamotridzhina [Correction of affective and cognitive impairment in patients with epilepsy and the importance of lamotrigine]. Nevrologiya, neyropsikhiatriya, psikhosomatika - Neurology, Neuropsychiatry, Psychosomatics. 2013; 5 (2): 7883 (in Russian).
4. Kissin M.Ya. Klinicheskaya epileptologiya [Clinical epileptology]. Second Edition. Moscow: GEOTAR-Media, 2011: 252 (in Russian).

5. Neznanov N.G., Kissin M.Ya. Psikhicheskiye rasstroystva pri epilepsii [Mental disorders in epilepsy] / edited by T.B. Dmitrieva, V.N. Krasnov, N.G. Neznanov and others. Moscow: GOETARMedia, 2009: 637-651 (in Russian).

6. Castro S., Baroni G., Martins W., Palmini A., Bisol L. Suicide risk, temperament traits, and sleep quality in patients with refractory epilepsy. Epilepsy Behav. 2018 Mar; 80: 254-258. DOI: 10.1016/j.yebeh.2018.01.022

7. Kalinin V.V., Zheleznova E.V., Zemlyanaya A.A., Sokolova L.V., Subbotin K.Yu. Depressii pri epilepsii: rasprostranennost', faktory riska, simptomatika i terapiya [Depression in epilepsy: prevalence, risk factors, symptoms and therapy]. Epilepsiya $i$ paroksizmal'nyye sostoyaniya - Epilepsy and Paroxysmal Diseases. 2017; 9 (3): 47-53 (in Russian). DOI: $10.17749 / 2077-8333.2017 .9 .3 .047-053$ 
8. Goncalves E.B., Cendes F. Depression in patients with refractory temporal lobe epilepsy. Arq Neuropsiquiatr. 2011 Oct; 69(5): 775-7. DOI: 10.1590/s0004-282x2011000600010

9. Ivanov M.V., Akimenko M.A. Opyt izucheniya neyromorfologicheskogo substrata affektivnykh rasstroystv v svyazi s problemoy terapevticheskoy rezistentnosti [The experience of studying the neuromorphological substrate of affective disorders in connection with the problem of therapeutic resistance]. Psikhiatriya $i$ psikhofarmakoterapiya Psychiatry and Psychopharmacotherapy. 2003; 5(2): 56-73(in Russian).

10. Hibar D.P., Westlye L.T., Doan N.T. et al. Cortical abnormalities in bipolar disorder: an MRI analysis of 6503 individuals from the ENIGMA Bipolar Disorder Working Group. Mol Psychiatry. 2018 Apr; 23(4): 932-942. doi: 10.1038/mp.2017.73

11. Kissin M.Ya., Ananyeva N.I., Shmeleva L.M., Ezhova R.V. Osobennosti neyromorfologii trevozhnykh i depressivnykh rasstroystv pri visochnoy epilepsii [Peculiarities of neuromorphology of anxiety and depressive disorders in case of temporal epilepsy]. Obozreniye psikhiatrii $i$ meditsinskoy psikhologii imeni V.M. Bekhtereva-Review of Psychiatry and Medical Psychology named after V.M. Bekhterev. 2012; 2: 11-17(in Russian).

12. Shamrey V.K., Trufanov G.E., Abritalin E.Yu., Korzenev A.V., Fokin V.A., Tarumov D.A., Dnov K.V., Lebedev A.V., Efimtsev A.Yu., Menshikova S.V. Sovremennyye metody neyrovizualizatsii v diagnostike depressivnykh rasstroystv [Modern methods of neuroimaging in the diagnosis of depressive disorders]. Vestnik Rossiyskoy Voyennomeditsinskoy akademii - Bulletin of the Russian Military Medical Academy. 2010; 1(29): 37-45 (in Russian).
13. Gulyaeva N.V. Neyroplastichnost' i epilepsiya: sovremennyye kontseptsii i mekhanizmy komorbidnosti epilepsii i depressii [Neuroplasticity and epilepsy: modern concepts and mechanisms of comorbidity of epilepsy and depression]. Zhurnal nevrologii i psikhiatrii imeni S.S. Korsakova - S.S,

14. Korsakov Journal of Neurology and Psychiatry. 2015; 115(12): 148-153 (in Russian).

15. Seung S. Konnektom. Kak mozg delayet nas tem, chto my yest': perevod s angliyskogo [Connectome. How the brain makes us what we are]: translation from English. Moscow: BINOM Publishing House, Knowledge Laboratory, 2014: 440 (in Russian).

16. Gong Q., He Y. Depression, neuroimaging and connectomics: a selective overview. Biol Psychiatry. 2014 Aug; 77(3): 223-235. DOI: 10.1016/j.biopsych.2014.08.009

17. Irimia A., Wang B., Aylward S.R. et al. Neuroimaging of structural pathology and connectomics in traumatic brain injury: toward personalized outcome prediction. Neuroimage Clin. 2012 Aug 24; 1(1): 1-17. doi: 10.1016/j.nicl.2012.08.002.

18. Irimia M., Weatheritt R.J., Ellis J. et al. A highly conserved program of neuronal microexons is misregulated in autistic brains. Cell. 2014 Dec; 159(7): 1511-23. DOI: 10.1016/j.cell.2014.11.035

19. Kalinin V.V., Zheleznova E.V., Zemlyanaya A.A., Sokolova L.V., Subbotin K.Yu. Depressii pri epilepsii: rasprostranennost', faktory riska, simptomatika i terapiya [Depression in epilepsy: prevalence, risk factors, symptoms and therapy]: Electronic resource. Epilepsiya i paroksizmal'nyye sostoyaniya - Epilepsy and Paroxysmal Diseases. 2017; 9 (3): 47-53. (in Russian). DOI: 10.17749/20778333.2017.9.3.047-053

Received October 21.2019 Accepted January 27.2020

Kapustina Tatiana V. - Ph.D., Researcher, Department of Treatment of Patients with Organic Mental Diseases and Epilepsy, V.M. Bekhterev National Medical Research Centre of Psychiatry and Neurology, St. Petersburg, Russian Federation. ORCID ID 0000-0001-8627-7550. Researcher ID T-1398-2018.

Ivanov Mikhail V. - MD, PhD, Professor, Chief Researcher, Head of the Department of Psychiatry V.M. Bekhterev National Medical Research Centre of Psychiatry and Neurology, St. Petersburg, Russian Federation. profmikhailivanov@gmail.com

Lipatova Lyudmila V. - MD, PhD, Professor, Department of Neurology and Psychiatry, Institute of Medical Education, V.A. Almazov National Medical Research Center. St. Petersburg, Russian Federation. ORCID ID 0000-00019988-3525. Scopus Author ID 36892509600. Researcher ID M-5928-2018. epilepsy-net@yandex.ru

Tumova Marianna A. - Junior Researcher of the Department of Psychiatry, V.M. Bekhterev National Medical Research Centre of Psychiatry and Neurology, St. Petersburg, Russian Federation. marianna_tumova@mail.ru

Kapustina Tatiana V., kapustina.tv7@gmail.com 